J. Clin. Chem. Clin. Biochem.

Vol. 14, 1976, pp. 31-36

\title{
Bestimmung des Thyroxin-bindenden Globulins (TBG) mit Hilfe des Competitive Ligand-Binding Assay (CLBA): Methodik und Ergebnisse
}

\author{
Von K. H. Rudorff ${ }^{1}$ ), J. Herrmann ${ }^{1}$ ), H. J. Kröll und H. L. Krüskemper
}

\section{Medizinische Universitätsklinik Düsseldorf}

(Eingegangen am 4. Juni/4. September 1975)

Zusammenfassung: Es wird über den Competitive Ligand-Binding Assay (CLBA), einen Test zur Bestimmung von Thyroxin-bindendem Globulin (TBG) im Serum berichtet, der erstmals von Chopra et al. ((1972), J. Clin. Endocrinol. Metab. 35, 565-573) beschrieben wurde. Die Bestimmung beruht auf der Verteilung einer konstanten Menge an markiertem Trijodthyronin $\left(\mathrm{T}_{3}\right)$ zwischen einer konstanten Menge an $\mathrm{T}_{3}$-Antikörpern und dem TBG des Serums, das zuvor durch Behandlung mit einem Anionenaustauscher (Amberlite IRA 400) von endogenem $T_{3}$ und $\mathrm{T}_{4}$ freigemacht wurde. Der TBG-Gehalt von Normalpersonen beträgt $25,5 \pm 5,0 \mathrm{mg} / 1\left(\overline{\mathrm{x}} \pm \mathrm{s}_{\mathrm{x}}\right)$; er ist signifikant erhöht bei Patienten mit Hypothyreose $(36,8 \pm 6,2 \mathrm{mg} / \mathrm{l})$, bei Schwangeren $(41,3 \pm 6,4 \mathrm{mg} / \mathrm{l})$ und signifikant erniedrigt bei Patienten mit Hyperthyreose (13,0 4,0 mg/l). Kein Unterschied besteht zwischen Normalpersonen und Frauen, die Kontrazeptiva mit einem niedrigen Östrogenanteil einnehmen. Es besteht eine signifikante negative Korrelation $z w i s c h e n$ TBG-Gehalt im Serum und dem relativen Anteil an freiem $T_{4}$ und freiem $T_{3}(r=-0,70, p<0,001)$. Der niedrige TBG-Gehalt bei hyperthyreoten Patienten normalisiert sich allmählich unter thyreostatischer Therapie; die erhöhten TBG-Gehalte bei Hypothyreose fallen unter Substitutionstherapie in den Normbereich ab. Es zeigt sich eine Abhängigkeit der TBG-Konzentration vom Lebensalter. Mit zunehmendem Lebensalter kommt es zu einem signifikanten Abfạl der TBG-Konzentration mit einem Minimum zwischen dem 20. und 50. Lebensjahr, danach erfolgt wieder ein signifikanter Anstieg auf die Ausgangswerte. Der CLBA-Assay ist eine einfache Routinemethode, die es ermöglicht, den TBG-Gehalt einer großen Anzahl an Serumproben genau und reproduzierbar zu messen. Der Vorteil gegenüber dem Radioimmunoassay für TBG liegt darin, daß eine Isolierung von TBG zur Antikörpergewinnung und Markierung mit radioaktiven Isotopen, was zur Zeit noch mit erheblichen methodischen Schwierigkeiten verbunden ist, nicht erforderlich ist.

\section{Measurement of thyroxine binding globulin by competitive ligand binding assay (CLBA)}

Summary: The competitive ligand binding assay (CLBA) first described by Chopra et al. ((1972) J. Clin. Endocrinol. Metab. 35, 565-573) is a convenient routine method for the accurate measurement of thyroxine binding globulin in large numbers of serum samples. The assay is based on the partition of a constant quantity of 'radiolabelled $\mathrm{T}_{3}$ between a fixed quantity of rabbit $T_{3}$ antibodies and the thyroxine binding globulin of the serum, after prior removal of $T_{3}$ and $T_{4}$ from the serum with an anion exchange resin (Amberlite IRA 400). In euthyroid subjects serum thyroxine binding globulin was $25.5 \pm 5.0 \mathrm{mg} / \mathrm{l}$, in hyperthyroid patients thyroxine binding globulin was significantly decreased to $13.0 \pm 4.0 \mathrm{mg} / \mathrm{l}$ and was significantly increased in hypothyroid patients to $36.8 \pm 6.2 \mathrm{mg} / \mathrm{l}$ as well as in pregniant women to $41.3 \pm 6.2 \mathrm{mg} / 1$. No difference was found between normal subjects and young women taking contraceptive pills with low oestrogen content. There were significant negative correlations between the thyroxine binding globulin in serum on the one hand side and the free $T_{4}$ - and free $T_{3}$-fraction on the other. The low thyroxine binding globulin estimates in hyperthyroid patients increased gradually to normal during treatment with thyroid blocking drugs, the elevated thyroxine binding globulin in hypothyroid patients decreased to normal during treatment with thyroid hormones. The competitive ligand binding assay used here seems to be convenient as a routine method for the precise and reproducible measurement of thyroxine binding globulin in serum.

1) Mit Unterstützung der Deutschen Forschungsgemeinschaft; auszugsweise vorgetragen auf dem 21 . Symposion der Deutschen Gesellschaft für Endokrinologie, München, 27. 2. - 2. 3. 1975. 


\section{Einführung}

Der periphere Metabolismus der beiden Schilddrüsenhormone Thyroxin und Trijodthyronin wird entscheidend beeinflußt durch die Bindung beider Hormone an Plasmaproteine. Bisher war ein befriedigendes Abschätzen des Ausmaßes der Proteinbindung nur indirekt möglich durch Messung der dialysablen Fraktionen beider Hormone bzw. durch Bestimmung der sog. $\mathrm{T}_{3}{ }^{2}$ ) resin uptake oder der maximalen Bindungskapazität von TBG für $\mathrm{T}_{4}$ durch Elektrophorese. Erst mit der Entwicklung einer radioimmunologischen Bestimmungsmethode ist es möglich geworden, die Konzentration des wichtigsten Bindungsproteins, des TBG direkt $\mathrm{zu}$ messen. Der Radioimmunoassay weist jedoch z. Zt, noch erhebliche methodische Schwierigkeiten auf. Daher erschien es wichtig, eine einfache, genaue und reproduzierbare Methode zur Bestimmung der TBG-Konzentration im Serum zu erarbeiten, die es ermöglicht, eine große Zahl von Serumproben zu messen und die für klinische Zwecke geeignet ist. In der folgenden Arbeit werden eine Modifikation des von Chopra et al. (1) entwickelten Competitive Ligand-Binding Assay zur Bestimmung von TBG im Serum beschrieben und die Ergebnisse klinischer Untersuchungen mit dieser Methode mitgeteilt. Die Modifikation besteht im wesentlichen in einem veränderten Inkubationsschema, das dem Vorgehen bei unserer radioimmunologischen Bestimmungsmethode für $T_{3}$ angepaßt wurde. Der CLBA beruht auf einer Verteilung einer konstanten Menge $\left[{ }^{125} \mathrm{~J}\right] \mathrm{T}_{3}$ zwischen einer definierten Menge an $\mathrm{T}_{3}$-Antikörpern und dem TBG des Serums, das zuvor durch Behandlung mit einem Anionenaustauscher (Amberlite IRA 400) vom endogenen $T_{3}$ und $T_{4}$ befreit wurde.

In die Bestimmungsmethode gehen folgende Charakteristika von TBG ein:

1. Proteinkonzentration

2. Bindungskapazität von TBG für $\left[{ }^{125} \mathrm{~J}\right] \mathrm{T}_{3}$

3. Affinität von $T B G$ für $\left[{ }^{125} \mathrm{~J}\right] \mathrm{T}_{3}$.

Wenn im Folgenden von der TBG-Konzentration gesprochen wird, so muß berücksichtigt werden, daß die Meßwerte auch Affinität und Bindungskapazität von TBG für T3 beinhalten, und es sich nicht um reine Konzentrationsangaben handelt.

\section{Methodik und Material}

$T_{3}$-Antikörper wurden durch Immunisierung von Kaninchen mit an Albumin gekoppeltem $\mathrm{T}_{3}$ gewonnen (2). Eine Endverdünnung von 1:25000 des Antiserums wurde in einem Gesamtvolumen von $1 \mathrm{ml}$ des Reaktionsgemisches verwendet. Bei

2) Abkürzungen:

CLBA = Competitive Ligand-Binding Assay

TBG = Thyroxin-bindendes Globulin

$T_{4}=$ Thyroxin

$\mathrm{T}_{3}=$ Trijodthyronin

ETR = Effective Thyroxine Ratio

TBPA = Thyroxin-bindendes Präalbumin
Inkubation mit markiertem $\mathrm{T}_{3}(\sim 0,15$ ng pro Ansatz) bei $37^{\circ} \mathrm{C}$ über 90 Minuten wurden $60-80 \%$ des Tracers an den Aritikörper gebunden; bei Inkubation mit einer Tracermenge an [ $\left.{ }^{125} \mathrm{~J}\right] \mathrm{T}_{4}$ wurden nur $1,5 \%$ des markierten $\mathrm{T}_{4}$ an $\mathrm{T}_{3}$-Antikörper gebunden.

Mit einem Barbitalpuffer 0,1 mol/1, pH 8,6 mit einem Zusatz an Rinderserumalbumin ( $1 \mathrm{~g} / \mathrm{l})$ wurden alle Lösungen angesetżt.

TBG-Standard: Ein Laborstandard wurde aus einem Serumpool von etwa 800 Normalpersonen gebildet. Die $T_{4}$-Konzentration betrug $96 \mu \mathrm{g} / \mathrm{l}$, die $\mathrm{T}_{3}$-Konzentration $1460 \mathrm{ng} / \mathrm{1}$, die ETR 0,96 . Der TBG-Gehalt des Standards betrug 26,0 mg/l. Als Referenzlösung diente ein Serum mit einem radioimmunologisch von Dr. Chopra, Los Angeles, gemessenen TBG-Gehalt von $51 \mathrm{mg} / 1$, das uns freundlicherweise von Herrn Dr. Hesch (Med. Hochschule Hannover) zur Verfügung gestellt wurde.

Präparation der Seren: Das Standardpoolserum sowie die Probanden-Seren wurden $T_{3} / T_{4}$ frei gemacht durch Inkubation von $1 \mathrm{ml}$ Serum mit 1,75 g Amberlite IRA 400 (Fa. Serva, Heidelberg) über $24 \mathrm{~h}$ bei Raumtemperatur. Mit einem aliquoten Volumen an Barbitalpuffer wurde das Serum aus dem Anionenaustauscher ausgewaschen. Wurde das Serum mit Tracermengen an [ $\left.{ }^{125} \mathrm{~J}\right] \mathrm{T}_{4}$ und $\left[{ }^{131} \mathrm{~J}\right] \mathrm{T}_{3}$ vorinkubiert, so verblieben nach Behancilung mit dem Anionenaustauscher $4,5 \%$ bzw. 3,0\% der Aktivität an Serumproteine gebunden. Die Effektivität der Hormonextraktion durch Amberlite wurde radioimmunologisch überprüft. In den extrahierten Seren konnten lediglich zwischen $0-150 \mathrm{ng} / 1 \mathrm{~T}_{3}$ und $0-10 \mu \mathrm{g} / 1 \mathrm{~T}_{4}$ nachgewiesen werden. Die Wirksamkeit der Hormonextraktion wurde weiterhin dadurch überprüft, daß nach Zusatz steigender Mengen an $T_{3}$ und $T_{4} z u$ einem Serum und nach Extraktion mit dem Anionenaustauscher die TBG-Gehalte der Seren gemessen wurden. Die Behandlung mit Amberlite erwies sich bis zu Serum $=\mathrm{T}_{3}-\mathrm{K}_{\text {onzentrationen }}$ von $8000 \mathrm{ng} / \mathrm{l}$ und Serum- $\mathrm{T}_{4}-$ Konzentrationen von $500 \mu \mathrm{g} / 1$ als ausreichend. Wurden den extrahierten Seren mehr als $200 \mathrm{ng} / 1 \mathrm{~T}_{3}$ hinzugefügt, so wurden zu hohe TBG-Gehalte gemessen.

Trijodthyronin und Thyroxin im Serum wurden radioimmunologisch $(2,3)$, die ETR mit einer früher beschriebenen Methode (4) gemessen. Der Anteil an freiem $T_{3}$ und $T_{4}$ wurden mit Hilfe der Gleichgewichtsdialyse bestimmt $(5) .\left[{ }^{125} \mathrm{~J}\right] \mathrm{T}_{4}$ und $\left[{ }^{125} \mathrm{~J}\right] \mathrm{T}_{3}$ wurden von der Fa. Byck Mallinckrodt bzw. von den Farbwerken Hoechst bezogen mit einer spezifischen Aktivität von $150 \mathrm{Ci} / \mathrm{g}$ bzw. $500 \mathrm{Ci} / \mathrm{g}$.

Versuchsanordnung (Abb. 1): In verschließbare Plastikröhrchen $(1 \times 5,5 \mathrm{~cm})$ werden nacheinander pipettiert:

1. $100 \mu 1$ 1:3 verdünntes Patienten-Serum bzw. 10-700 $\mu \mathrm{l}$ $1: 3$ verdünntes Standard-Pool-Serum entsprechend $0,065-$ 4,55 $\mu \mathrm{g}$ TBG pro Arisatz;

2. $100 \mu 1 \mathrm{~T}_{3}$ Antiserum 1:2500 verdünnt;

3. $100 \mu\left[[125 \mathrm{~J}] \mathrm{T}_{3}(\sim 0,15 \mathrm{ng})\right.$;

4. Barbitalpuffer $0,1 \mathrm{~mol} / 1, \mathrm{pH} 8,6$ ad $1,0 \mathrm{ml}$;

5. Schütteln und Inkubation bei $37^{\circ} \mathrm{C}$ über 90 Minuten, anschließend Abkühlung auf Raumtemperatur;

6. Abtrennung der an $\mathrm{T}_{3}$-Antikörper gebundenen Aktivität durch Fälluing mit $50 \mu 1$ anti-Kaninchen- $\gamma$-Globulin (Esel) 1:200 verdïnnt (Deutsche Welloome $\mathrm{GmbH}$ ) und $20 \mu \mathrm{l}$ Kaninchenserụm 1:40 verdünnt.

Anschließend Inkubation über $4 \mathrm{~h}$ bei Raumtemperatur; Zentrifugieren ( $5 \mathrm{~min}$ bei $2500 \mathrm{~g}$ ), Überstand absaugen. Messung des Rückstandes (an $T_{3}$-Antikörper verbliebene $\left[{ }^{125} \mathrm{~J}\right] \mathrm{T}_{3}$-Aktivität) im Gamma-Zählgerät.

\section{Ergebnisse}

Abbildung 2 zeigt den typischen Verlauf der Standardkurven und veranschaulicht deren Reproduzierbarkeit .

- Die Präzision in Serie wies einen Variationskoeffizienten von $\pm 3 \%(n=15)$, die Präzision von Tag żu Tag, gemessen über einen Zeitraum von 6 Monaten $(n=15)$, einen Variationskoeffizienten von $\pm 5,9 \%$ auf. 


\section{VORBEREITUNG ( $T_{3}$-EXTRAKTION)}

$1 \mathrm{ml}$ Serum bzw. STANDARD

$+1,75$ g Amberlite IRA 400

INKUBATION $24 \mathrm{~h}$ ca. $22^{\circ} \mathrm{C}$
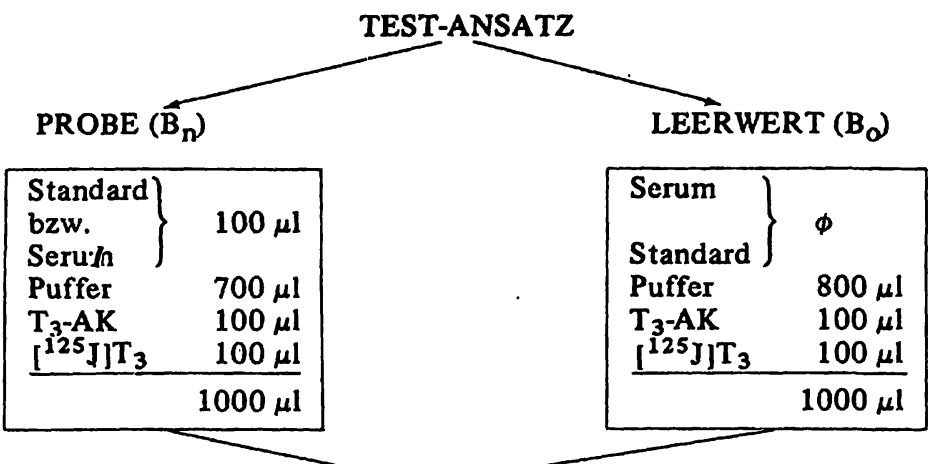

MISCHEN, INKUBATION $\left(90 \mathrm{~min}, 37^{\circ} \mathrm{C}\right)$, ABKÜHLEN TRENNUNG

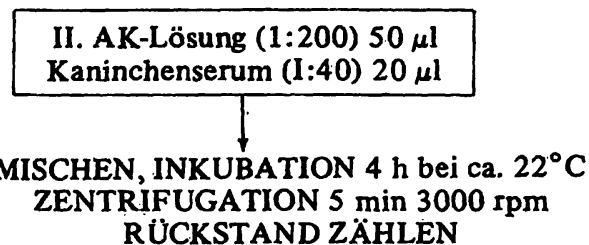

Abb. 1. Versuchsanordnung des Competitive Ligand-Binding Assay zur Bestimmung von Thyroxin-bindendem Globulin im Serum.

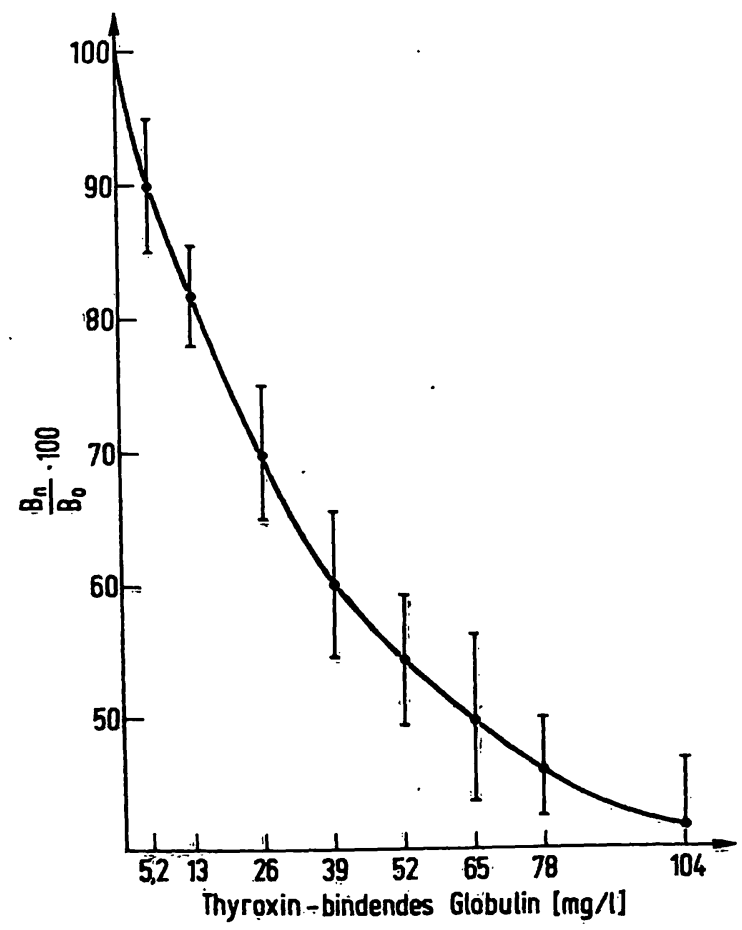

Abb. 2. Reproduzierbarkeit der Eichkurven.
Der CLBA ermöglicht bei einem 1:3 verdünnten Serumvolumen von $100 \mu$ l eine Messung über einen Bereich von $2,6-132 \mathrm{mg} / \mathrm{l}$. Human-Serumalbumin hatte bis zu einer Konzentration von $2 \mathrm{mg} / 100 \mu 1$ 1:3 verdünntem Serum (dies entspricht einer Konzentration von $80 \mathrm{~g} / \mathrm{l}$ Albumin im Vollserum) keinen signifikanten Einfluß auf die Bindungskurven. Nur bei höheren Albuminkonzentrationen wurden zu hohe TBG-Gehalte gemessen. Durch Verwendung von Barbitalpuffer wurde eine Bindung von $T_{3}$ an TBPA verhindert und somit eine Beeinflussung der kompetitiven Bindung von $T_{3}$ durch TBG und $T_{3}$-Antikörper durch TBPA ausgeschaltet. (13).

Eine zufriedenstellende Trennung der an $T_{3}$-Antikörper gebundenen Aktivität von der an TBG gebundenen und von der ungebundenen Aktivität ließ sich mit antiKaninchen- $\gamma$-Globulin (Esel) durchführen. In Testansätzen ohne $\mathrm{T}_{3}$-Antikörper konnte im Präzipitat keine Radioaktivität nachgewiesen werden, was darauf hinweist, daß kein TBG vom anti-Kaninchen- $\gamma$-Globulin präzipitiert wird.

Die Wiederfindungsrate betrug bei TBG-Konzentrationen bis $70 \mathrm{mg} / 1$ 90-98\%, bei Konzentrationen von $70-130 \mathrm{mg} / 1$ 85-90\% der eingesetzten Menge.

Abbildung 3 zeigt den Vergleich von Bindungskurven jeweils eines Poolserums von hyperthyreoten und mit Östrogenen behandelten Patienten mit unserem Standardpool-Serum. Die parallelen Kurvenverläufe beweisen die Vergleichbarkeit der Bindungsaffinitäten von TBG in Normalseren und Seren mit erniedrigten bzw. erhöhten TBG-Gehalten. Diese Befunde sind Voraussetzung für die Richtigkeit des CLBA für TBG und unterstützen die Annahme; daß sowohl erworbene als auch kongenitale Abnormitäten des Serum-TBG prinzipiell mit Konzentrationsänderungen und nicht mit Veränderungen der Bindungsaffinität einhergehen.

In Tabelle 1 sind die gemessenen. TBG-Konzentrationen für Normalpersonen, hyper- und hypothyreote Patienten

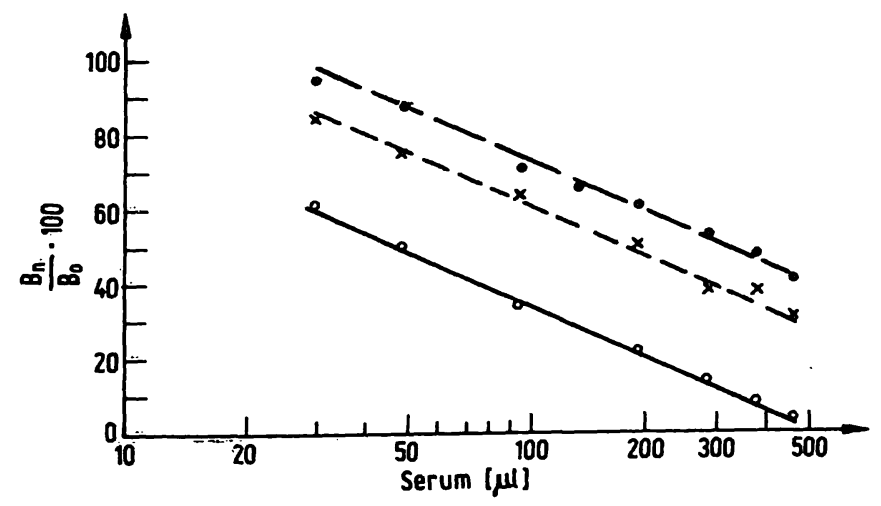

Abb. 3. Vergleich der Bindungskurven von Seren von Normalpersonen $(x-x)$, von Hyperthyreosen $(.-.-)$ und von Patienten unter Ostrogentherapie $(0-0)$. 
Tab. 1. Serum-TBG- und Schilddrüscnhormonkonzentrationen bei Eu-, Hyper- und Hypothyreose und Gravidität; $(\overline{\mathrm{X}} \pm$ s); $t_{p}<0,0125,{ }_{p}^{++}<0,005$ gegenüber Euthyreose.

\begin{tabular}{|c|c|c|c|c|c|c|c|c|}
\hline & \multirow{2}{*}{$\begin{array}{l}\text { TBG } \\
{[\mathrm{mg} / 1]}\end{array}$} & \multirow{2}{*}{$\begin{array}{l}T_{4} \\
{[\mu g / 1]}\end{array}$} & \multicolumn{2}{|c|}{ freies $T_{4}$} & \multirow{2}{*}{$\begin{array}{l}\hat{\mathrm{T}}_{4}(\mu \mathrm{g} / \mathrm{l}) / \\
\mathrm{TBG}(\mathrm{mg} / \mathrm{l})\end{array}$} & \multirow{2}{*}{$\begin{array}{l}T_{3} \\
\text { [ng/l] }\end{array}$} & freies $T_{3}$ & \multirow{2}{*}{$\begin{array}{l}T_{3}(\mathrm{ng} / \mathrm{l}) / \\
\mathrm{TBG}(\mathrm{mg} / \mathrm{l})\end{array}$} \\
\hline & & & {$[\mathrm{ng} / \mathrm{l}]$} & {$[\%]$} & & & [ng/l] & \\
\hline $\begin{array}{l}\text { Euthyreose } \\
\text { (37) }\end{array}$ & $\begin{array}{r}25,5 \\
\pm \quad 5,0\end{array}$ & $\begin{array}{r}83,0 \\
\pm \quad 14,0\end{array}$ & $\begin{array}{r}17,4 \\
\pm \quad 4,7\end{array}$ & $\begin{array}{r}0,021 \\
\pm 0,005\end{array}$ & $\begin{array}{r}3,21 \\
\pm \quad 0,84\end{array}$ & $\begin{array}{r}1408 \\
\pm \quad 465\end{array}$ & $\begin{array}{rr}2,82 & 0,20 \\
\pm 0,25 & \pm 0,03\end{array}$ & $\begin{array}{r}55,2 \\
\pm \quad 17,8\end{array}$ \\
\hline $\begin{array}{l}\text { Hyperthyreose } \\
(40)\end{array}$ & $\begin{array}{l}13,0^{++} \\
\pm \quad 4,0\end{array}$ & $\begin{array}{l}200,0^{++} \\
\pm 30,0\end{array}$ & $\begin{aligned} & 68,0++ \\
\pm & 18,5\end{aligned}$ & $\begin{aligned} & 0,034^{++} \\
\pm & 0,016\end{aligned}$ & $\begin{array}{l}15,4^{++} \\
\pm \quad 5,0\end{array}$ & $\begin{aligned} & 4662^{++} \\
\pm & 1875\end{aligned}$ & 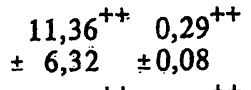 & $\begin{aligned} & 358,4^{++} \\
\pm & 152,0\end{aligned}$ \\
\hline $\begin{array}{l}\text { Hypothýreose } \\
\text { (18) }\end{array}$ & $\begin{array}{l}36,8^{++} \\
\pm \quad 6,2\end{array}$ & $\begin{array}{ll} & 31,0^{++} \\
\pm & 17,0\end{array}$ & $\begin{aligned} & 4,7^{++} \\
\pm & 2,4\end{aligned}$ & $\begin{aligned} & 0,016^{++} \\
\pm & 0,004\end{aligned}$ & $\begin{array}{ll} & 0,88^{++} \\
\pm & 0,72\end{array}$ & $\begin{aligned} & 444^{++} \\
\pm & 361\end{aligned}$ & 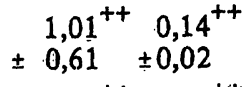 & $\begin{array}{c}12,0^{++} \\
\pm \quad 8,7\end{array}$ \\
\hline $\begin{array}{l}\text { Gravidität } \\
\text { (16) }\end{array}$ & $\begin{array}{l}\quad 41,3^{++} \\
\pm 6,2\end{array}$ & $\begin{array}{r}105,0^{+} \\
\pm \quad 13,0\end{array}$ & $\begin{array}{l}12,6^{++} \\
\pm 3,0\end{array}$ & $\begin{aligned} & 0,012^{++} \\
\pm & 0,003\end{aligned}$ & $\begin{array}{ll} & 2,54^{++} \\
\pm & 0,33\end{array}$ & $\begin{array}{l}1691^{++} \\
\pm \quad 247\end{array}$ & $\begin{aligned} & 2,21^{++} 0,13^{++} \\
\pm & 0,41 \quad \pm 0,02\end{aligned}$ & $\begin{array}{c}41,2^{++} \\
\pm \quad 8,5\end{array}$ \\
\hline
\end{tabular}

und Gravide mit den entsprechenden Daten für Gesamt$\mathrm{T}_{4}$ und $\mathrm{T}_{3}$, prozentuales freies $\mathrm{T}_{4}$ und $\mathrm{T}_{3}$ sowie für die Konzentrationen der freien Hormone wiedergegeben. Außerdem enthält die Tabelle die Quotienten

$\frac{\mathrm{T}_{4}(\mu \mathrm{g})}{\mathrm{TBG}(\mathrm{mg})}$ und $\frac{\mathrm{T}_{3}(\mathrm{ng})}{\mathrm{TBG}(\mathrm{mg})}$

mit denen sich eine Differenzierung der Schilddrüsenfunktionen bei Bindungsabnormalitäten im Serum erzielen läßt, wie es in Tabelle 1 an dem Beispiel von Graviden dargestellt ist. Bei den Graviden sind die TBGKonzentrationen im Serum bei leicht erhöhtem Gesamt$\mathrm{T}_{4}$ und $\mathrm{T}_{3}$ stark erhöht. Die Quotienten $\mathrm{T}_{4} / \mathrm{TBG}$ und $\mathrm{T}_{3} / \mathrm{TBG}$ sind gegenüber den Quotienten bei Eutyhreose signifikant erniedrigt. Dies deutet auf einen Mangel an freiem $T_{4}$ und $T_{3}$ hin, was durch die direkte Messung der freien Hormonfraktionen bestätigt wird (Tab. 1). Bei Hyper- und Hypothyreose treten die Veränderungen in den Serumkonzentrationen deutlicher hervor, wenn die Ergebnisse auf den TBG-Gehalt bezogen und pro mg TBG angegeben werden (Tab. 1).

Die TBG-Konzentrationen $(24,3 \pm 2,9 \mathrm{mg} / 1, \mathrm{n}=10)$ bei Frauen, die hormonelle Kontrazeptiva mit einem niedrigen Östrogenanteil einnehmen (0,05 mg Ethinylöstradiol) unterscheiden sich nicht von Normalpersonen $(25,5 \pm 5,0 \mathrm{mg} / \mathrm{l}, \mathrm{n}=37)$. Unter Testosterontherapie $(13,4 \pm 5,0 \mathrm{mg} / \mathrm{l}, \mathrm{n}=6)$ und bei dekompensierter Lebercirrhose $(10,0 \pm 3,0 \mathrm{mg} / \mathrm{l}, \mathrm{n}=8)$ sind die TBG-Konzen- trationèn gegenüber der Norm signifikant erniedrigt, unter Östrogentherapie (360 mg Tetranatrium diaethylstilboestroldiphosphoricum tgl. oral u. $80 \mathrm{mg}$ Polyöstradiolphosphat i. m. alle drei Wochen) signifikant erhöht $(44,2 \pm 6,0 \mathrm{mg} / 1, \mathrm{n}=3)$. Der erniedrigte TBGGehalt bei hyperthyreoten Patienten normalisiert sich allmählich unter thyreostatischer Therapie, die erhöhten TBG-Konzentrationen bei Hypothyreose fallen unter Substitutionstherapie in den Normbereich ab (Tab. 2).

Abbildung 4 veranschaulicht die Beziehung $z$ wișchen TBG-Gehalt und relativen Anteilen an freiem $\mathrm{T}_{4}$ und $\mathrm{T}_{3}$ im Serum. Es besteht eine signifikante negative Korrelation, $\mathrm{r}=-0,70$ bzw. $-0,69$.

Tabelle 3 zeigt die Ergebnisse der Untersuchungen über die Abhängigkeit der TBG-Konzentration vom Lebensalter. Mit zunehmendem Lebensalter kommt es zunächst zu einem Abfall der Serum-TBG-Konzentration mit einem Minimum zwischen dem 20.-50. Lebensjahr, danach steigt im höheren Lebensalter das TBG wieder signifikant an. Ein Geschlechtsunterschied der TBGKonzentrationen wirde in keiner Altersgruppe beobachtet.

\section{Diskussion}

Der CLBA für TBG ist eine einfache, präzise und reproduzierbare Methode, die es erlaubt, die TBG-Gehalte einer größeren Anzahl an Serumproben zu messen. In

Tab. 2. Einfluß von Thyreostatika bzw. Substitutionstherapie auf die TBG-Konzentration im Serum von hyperthyreoten bzw. hypothyreoten Patienten.

\begin{tabular}{|c|c|c|c|c|c|c|c|c|c|c|}
\hline & \multirow[b]{3}{*}{ Patient } & \multirow{2}{*}{\multicolumn{3}{|c|}{ Vor Therapiebeginn }} & \multirow{2}{*}{\multicolumn{6}{|c|}{$\begin{array}{l}\text { unter Thyreostatika bzw. Substitution } \\
2-4 \text { Wochẹn } \\
4-8 \text { Wochen }\end{array}$}} \\
\hline & & & & & & & & & & \\
\hline & & $\begin{array}{l}\text { TBG } \\
{[\mathrm{mg} / \mathrm{l}]}\end{array}$ & $\begin{array}{l}\text { freies } T_{4} \\
{[\%]}\end{array}$ & $\begin{array}{l}\text { freies } \mathrm{T}_{3} \\
{[\%]}\end{array}$ & $\begin{array}{l}\text { TBG } \\
{[\mathrm{mg} / \mathrm{l}]}\end{array}$ & $\begin{array}{l}\text { freies } \mathrm{T}_{4} \\
{[\%]}\end{array}$ & $\begin{array}{l}\text { freies } \overline{\mathrm{T}}_{3} \\
{[\%]}\end{array}$ & $\begin{array}{l}\mathrm{TBG} \\
{[\mathrm{mg} / \mathrm{l}]}\end{array}$ & $\begin{array}{l}\text { freies } T_{4} \\
{[\%]}\end{array}$ & $\begin{array}{l}\text { freies } T_{3} \\
{[\%]}\end{array}$ \\
\hline Hyperthyreose & $\begin{array}{l}\text { B. G. } \\
\text { A. A. } \\
\text { Z. E. }\end{array}$ & $\begin{array}{l}12,8 \\
16,5 \\
1 !, 5\end{array}$ & $\begin{array}{l}0,045 \\
0,060 \\
0,090\end{array}$ & $\begin{array}{l}0,353 \\
0,410 \\
0,511\end{array}$ & $\begin{array}{r}26,0 \\
29,9 \\
.21,5\end{array}$ & $\begin{array}{l}0,028 \\
0,017 \\
0,040\end{array}$ & $\begin{array}{l}0,226 \\
0,146 \\
0,284\end{array}$ & $\begin{array}{l}29,7 \\
28,6 \\
28,4\end{array}$ & $\begin{array}{l}0,025 \\
0,022 \\
0,020\end{array}$ & $\begin{array}{l}0,222 \\
0,220 \\
0,188\end{array}$ \\
\hline Hypothyreose & $\begin{array}{l}\text { W. A. } \\
\text { W. G. } \\
\text { G. H. }\end{array}$ & $\begin{array}{l}41,6 \\
51,4 \\
46,0\end{array}$ & $\begin{array}{l}0,017 \\
0,018 \\
0,016\end{array}$ & $\begin{array}{l}0,122 \\
0,139 \\
0,130\end{array}$ & $\begin{array}{l}38,4 \\
29,0 \\
32,0\end{array}$ & $\begin{array}{l}0,018 \\
0,022 \\
0,020\end{array}$ & $\begin{array}{l}0,143 \\
0,200 \\
0,190\end{array}$ & $\begin{array}{l}29,3 \\
16,9 \\
24,0\end{array}$ & $\begin{array}{l}0,020 \\
0,073 \\
0,025\end{array}$ & $\begin{array}{l}0,180 \\
0,457 \\
0,220\end{array}$ \\
\hline
\end{tabular}



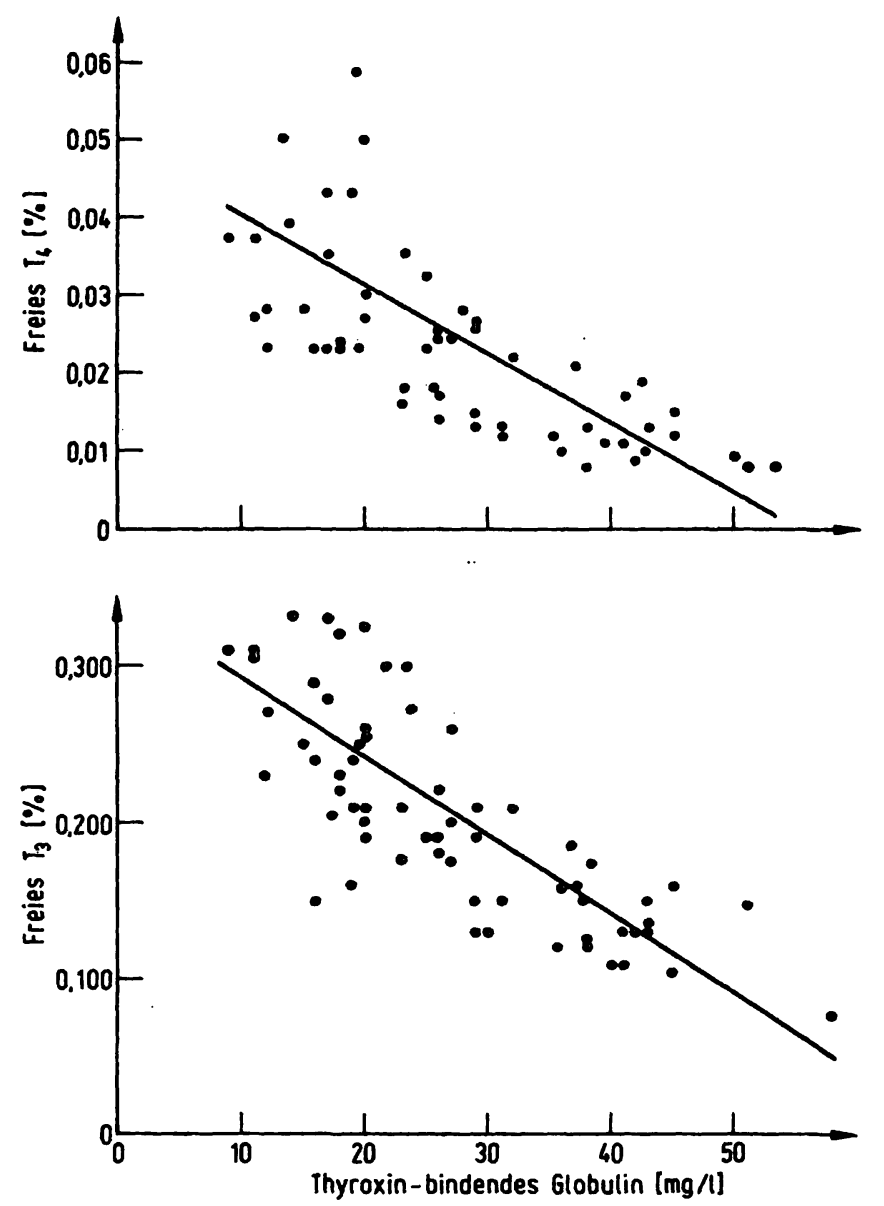

Abb. 4. Beziehung zwischen TBG (mg/l) und prozentualem freien T4 $(y=0,049-0,009 x, r=-0,70, n=57)$ und prozentualem freien $\mathrm{T} 3(y=0,34-0,05 x, r=-0,69, n=65)$.

Tab. 3. Abhängigkeit der Serum-TBG-Konzentrationen vom Lebensalter. $(\bar{x} \pm s),{ }^{+} p<0,005$ gegenüber den Altersgruppen 1-19 Jahren und 50-80 Jahren.

\begin{tabular}{cl}
\hline $\begin{array}{l}\text { Lebensalter } \\
\text { in Jahren }\end{array}$ & $\begin{array}{l}\text { TBG-Konzentrationen } \\
{[\mathrm{mg} / 1]}\end{array}$ \\
\hline $1-9$ & $23,1 \pm 6,3$ \\
& $(55)$ \\
$10-19$ & $22,3 \pm 5,9$ \\
& $(28)$ \\
$20-29$ & $17,7 \pm 5,7^{+}$ \\
& $(21)$ \\
$30-39$ & $17,6 \pm 3,2^{+}$ \\
$40-49$ & $(19)$ \\
& $16,4 \pm 2,5^{+}$ \\
$50-59$ & $(18)$ \\
& $20,2 \pm 4,1$ \\
$60-69$ & $(14)$ \\
& $19,1 \pm 5,9$ \\
$70-79$ & $(15)$ \\
& $21,1 \pm 6,5$ \\
& $(20)$ \\
& $20,4 \pm 3,7$ \\
& $(15)$ \\
\hline
\end{tabular}

einem Versuchsansatz können $60-80$ Serumproben bestimmt werden, die Versuchşauer einschließlich der Vorbereitung der Seren beträgt 2 Tage. Hierin liegt der große Vorteil gegenüber der üblichen elektrophoreti- schen Methode (6) zur Quantifizierung von TBG durch Bestimmung seiner maximalen $\mathrm{T}_{4}$-Bindungskapazität, die mit einem erheblichen Zeitaufwand verbunden ist. Der CLBA ist vergleichbar mit dem Radioimmunoassay für TBG (7) hinsichtlich der Genauigkeit und der Leistungsfähigkeit. Die Empfindlichkeit des Radioimmunoassay ist größer. Es können Serumkonzentrationen bis $20 \mu \mathrm{g} / \mathrm{l}$ nachgewiesen werden, während die untere Nachweisgrenze beim CLBA bei Verwendung von $100 \mu \mathrm{l} 1: 3$ verdünntem Probenserum bei $2,6 \mathrm{mg} / 1$ liegt. Die Empfindlichkeit des CLBA reicht jedoch aus, da TBG-Konzentrationen unter $2,6 \mathrm{mg} / \mathrm{l}$ außerordentlich selten sind. Der CLBA unterscheidet sich vom Radioimmunoassay darin, daß er mehr von der Funktion als von der Struktur des TBG abhängig ist. Die Meßergebnisse des CLBA werden außer von der Proteinkonzentration von TBG auch von der Bindungskapazität und von der Affinität von TBG für ${ }^{125} \mathrm{~J}$-markiertes $\mathrm{T}_{3}$ beeinflußt. Funktionell inaktive TBG-Moleküle gehen nicht mit in das Testergebnis ein. Wir sehen hierin keinen Nachteil gegenüber dem Radioimmunoassay für TBG, sondern eher einen Vorteil, da der CLBA außer einer Aussage über die Konzentration auch eine Information über die Funktion des TBG liefert.

Sowohl erworbene als auch kongenitale Abnormitäten des Serum-TBG gehen mit Konzentrationsänderungen einher und nicht mit Veränderungen der Bindungsaffinität $(1,8)$, wie es früher vermutet wurde (9). Diese Aussage, die von Bedeutung für die Richtigkeit des CLBA ist, wird unter anderem durch die Vergleichbarkeit der Bindungskurven von Normalpersonen mit denen von Patienten mit erworbenen TBG-Veränderungen (Abb. 3) gestützt. Der Radioimmunoassay ist dagegen abhängig von einer schonenden und reinen Isolierung des TBG aus dem Serum. Während der Präparation kann es leicht zu Veränderungen der Struktur und damit der Antigenität von TBG kommen, was zu unterschiedlichen Bindungskurven führen kann, wenn verschiedene Chargen von isoliertem TBG mit demselben Antiserum reagieren.

Von Sterling et al. (15) wird berichtet, daß eine Behandlung von TBG mit Ionenaustauschern zu einer Änderung der Bindungsverhältnisse für Schilddrüsenhormone führt. Dies scheint jedoch nicht für eine Vorbehandlung mit Amberlite IRA 400 zuzutreffen. Wir haben mit Hilfe des „Scatchard plot" (14) vor und nach Extraktion des Poolserums mit Amberlite IRA 400 die maximale Bindungskapazität von TBG für $T_{4}$ sowie die ThyroxinAssoziationskonstanten für TBG bestimmt. Diese Parameter werden durch die Extraktion nicht beeinflußt. Vor Extraktion betrug die maximale Bindungskapazität von TBG für $\mathrm{T}_{4} 185 \mu \mathrm{g} / \mathrm{l}$, nach Extraktion $180 \mu \mathrm{g} / \mathrm{l}$. Die Thyroxinassoziationskonstante lag vor der Extraktion bei $4,5 \times 10^{8} \mathrm{l} / \mathrm{mol}$, nach Extraktion bei $5,6 \times 10^{8} 1 / \mathrm{mol}$. Obgleich die Assoziationskonstanten methodisch bedingt zu niedrig gemessen werden, können doch die Werte miteinander verglichen werden. Außerdem ist auch eine 
enge Korrelation zwischen der maximalen Bindungskapazität von TBG für $\mathrm{T}_{4}$ und den mit Hilfe des CLBA gemessenen TBG-Konzentrationen nachgewiesen wor$\operatorname{den}(1)$.

Der CLBA erfordert ein $\mathrm{T}_{3}$-bindendes Antiserum, das eine hohe Affinität zu $T_{3}$ besitzt, so daß $T_{3}$-bindende Proteine mit niedriger Affinität zu $\mathrm{T}_{3}, \mathrm{z}$. B. Serumalbumin nicht interferieren. Der Testanordnung mit $T_{3}$ und $\mathrm{T}_{3}$-Antiserum wird bei dem CLBA für TBG gegenüber $\mathrm{T}_{4}$ und $\mathrm{T}_{4}$-Antiserum der Vorzug gegeben, da Experimente gezeigt haben, daß mit der ersten Kombination Änderungen der TBG-Konzentration deutlicher werden (1). Bei den von uns untersuchten Graviden ist der TBG-Gehalt signifikant erhöht. Obgleich das Gesamt- $\mathrm{T}_{4}$ und $-\mathrm{T}_{3}$ gegenüber Normalpersonen erhöht ist, ist das prozentuale freie $T_{4}$ und $T_{3}$ signifikant erniedrigt. Es wird durch den Anstieg des Gesamt- $\mathrm{T}_{4}$ und $-\mathrm{T}_{3}$ nicht ausreichend kompensiert, so daß dadurch die Konzentration an freiem $\mathrm{T}_{4}$ und $\mathrm{T}_{3}$ als Stellgröße ebenfalls erniedrigt ist. Dies kommt auch zum Ausdruck, wenn $\mathrm{T}_{4}$ und $\mathrm{T}_{3}$ pro mg TBG berechnet werden (Tab. 1). Diese Befunde können ein Hinweis für eine latente Hypothyreose bei Graviden sein. Hierfür spricht neben der klinischen Beobachtung eines gehäuften Auftretens von Strumen auch der Befund von erhöhten basalen Thyrotropin-Konzentrationen bei Graviden (10). Die erhöhten basalen Thyrotropin-Konzentrationen könnten allerdings auch durch unspezifische Kreuz- reaktionen in der Schwangerschaft verursacht worden sein.

Am Beispiel von hyper- und hypothyreoten Patienten kann gezeigt werden, daß unter einer entsprechenden Therapie sich gleichzeitig mit den Hormonkonzentrationen die TBG-Konzentrationen normalisieren. (Abb. 3). Die enge Korrelation zwischen TBG- und Hormonkonzentrationen gehen auch aus Tabelle 1 und Abbildung 4 hervor. Die Untersuchungen über die Abhängigkeit der TBG-Konzentrationen vom Lebensalter ergaben, daß die TBG-Konzentrationen zunächst vom Kindes- zum Erwachsenenalter abfallen, mit einem Minimum zwischen dem 20. - 50. Lebensjahr, danach kömmt es im höheren Lebensalter wieder $\mathrm{zu}$ einem signifikanten Anstieg (Tab. 3). Ein entspprechender Kurvenverlauf wird von Braverman et al. (11) für die maximale Bindungskapazität von TBG für $\mathrm{T}_{4}$ beschrieben. Die maximale Bindungskapazität für TBPA steigt dagegen mit zunehmendem Alter an mit einem Maximum zwischen 20-50 Jahren, um dann im höheren Lebensalter wieder abzufallen. Die Gesamtbindungskapazität des Serums für $\mathrm{T}_{4}$ und $\mathrm{T}_{3}$ ändert sich somit nicht (11). Der allmähliche Rückgang der Umsatzrate für $\mathrm{T}_{4}$ in der Peripherie mit zunehmendem Lebensalter und der von Herrmann et al. (12) beobachtete Abfall der Gesamt- $\mathrm{T}_{3}$-Serumkonzentrationen läßt sich demnach nicht mit einer Änderung der Bindungskapazitäten für Schilddrüsenhormone im hohen Lebensalter. erklären.

\section{Literatur}

1. Chopra, I. J., Solomon, D. H. \& Ho, R. S., (1972), J. Clin. Endocrinol. Metab. 35, 565-573.

2. Hilger, P., Herrmann, J. \& Krüskemper, H. L. (1973), diese Z. $11,323$.

3. Herrmann, J., Rusche, H. J. \& Krüskemper, H. L. (1974), Clin. Chim. Acta 54, 69-79.

4. Rudorff, K. H., Herrmann, J. \& Krüskemper, H. L. (1973), diese Z. 11, 259-262.

5. Herrmann, J. \& Krüskemper, H. L., (1971), diese Z. 9, $320-323$.

6. Herrmann, J., Bahlmann, J. \& Krüskemper, H. L., (1972), Acta Endocrinol., 69, 13-28.

7. Levy, R. P., Marshall, J. S. \& Velayo, H. L. (1971), J. Clin. Endocrinol. Metab. 32, 372-381.

8. Refetoff, S., Hagen, S. R. \& Selenkow, H. A. (1972), J. Nucl. Med., 13, 2.

9. Marshall, J. S. \& Pensky, J., (1969), J. Clin. Invest. 48, 508.

10. Rastogi, G. H., Sawhney, R. C., Thomas, Z. \& Devi, P. K.. (1974) Obstet. Gynecol., 44, 176-180.

11. Braverman, L. E., Dawber, N. A. \& Ingbar, S. H., (1966), J. Clin. Invest. 45, 1273-1279.

12. Herrmann, J., Rusche, J., Kröll, H. J., Rudorff, K. H. \& Krüskẹmper, H. L., (1974), Deut. Med. Wochenschr. 99, 2122-2124.

13. Ingbar, S. H. (1963), J. Clin. Invest. 42, 143-160.

14. Keane, P. M., Pegg, P. J. \& Johnson, E. (1969), J. Clin. Endocr. 29, 1126-1130.

15. Sterling, K., Hamada, S., Tạkemura, Y., Brenner, M. A., Newman, E. S. \& Inada, M., (1971), J. Clin. Invest. 50, 1758-1771.
Dr. K-H. Rudorff

Prof. Dr. $\dot{J}$. Herrmann

cand. med. H. J. Kröll

Prof. Dr. H. L. Krüskemper

II. Medizinische Unniversitätsklinik 4000 Dïsseidorf

Moorenstraße 5 